\title{
Assessment of community health volunteers' knowledge on cervical cancer in Kadibo Division, Kisumu County: a cross sectional survey
}

Edwin Onyango Ochomo ${ }^{1 *}$, Harrysone Atieli ${ }^{1}$, Sussy Gumo ${ }^{2}$ and Collins Ouma ${ }^{1,3}$

\begin{abstract}
Background: Globally, cervical cancer is the fourth most frequent cancer in women, with an estimated 530,000 new cases in 2012, representing 7.5\% of all female cancer deaths. Of the estimated more than 270,000 deaths from cervical cancer every year, more than $85 \%$ occur in less developed regions. In sub-Saharan Africa, 34.8 new cases of cervical cancer are diagnosed per 100,000 women annually, and 22.5/100,000 women die from the disease. Despite the magnitude of this problem, Kenya still has a screening rate of 3.2\%; therefore, cervical cancer prevalence has not been established. Community Health Volunteers (CHV) are required to create demand for screening in the community and capture this in the Ministry of Health $(\mathrm{MOH})$ reporting tool $\mathrm{MOH} 514$. The objective of this study was to determine the knowledge of risk factors, signs and symptoms of cervical cancer and screening services' availability amongst CHVs to enable them sensitize the community about cervical cancer in Kadibo Division, Kisumu County.
\end{abstract}

Method: In a cross-sectional study, a saturated sample of 188 CHVs was interviewed. The knowledge of cervical cancer was presented by use of frequencies and proportions; the relationship between demographic characteristics and knowledge was determined using chi-square.

Results: A majority, 161 (85.6\%), were women, 47 (25.0\%) were aged 40-44, 91 (48.4\%) had primary education and $132(70.2 \%)$ were small-scale farmers. A total of 128 (68.1\%) had low, 60 (31.9\%) had average and none had high amount of knowledge of risk factors. On average, 95 (50.5\%) had low, 15 (8.0\%) had average and 78 (41.5\%) had high amount of knowledge of signs and symptoms. Finally, 77 (41.0\%) had high, 40 (21.2\%) had average and 71 (37.8\%) had low knowledge of the availability of screening services. Education $\left(p=0.012, x^{2}=3.839\right)$, occupation $\left(p<0.0001, x^{2}=12.722\right)$, and health centre of attachment $\left(p<0.0001, x^{2}=71.013\right)$ were significant factors in determining the knowledge of risk factors. The knowledge of the signs and symptoms of cervical cancer was determined by the occupation of the $\operatorname{CHVs}\left(p=0.030, x^{2}=15.110\right)$ and the years of work as a CHV $\left(p=0.014, x^{2}=8.451\right)$. Finally, the education level $\left(p=0.011, x^{2}=8.605\right)$, occupation $\left(p=0.002, x^{2}=18.335\right)$ and health centre of attachment $(p<0.0001$, $\left.x^{2}=101.705\right)$ were significant in determining the knowledge of availability of screening services at the various health facilities.

Conclusion: The following were found to significantly influence the knowledge of CHVs about cervical cancer: level of education, occupation, health facility of attachment and years of service as a CHV. There is need, therefore, for training on cervical cancer.

Keywords: Community health volunteers, Knowledge, Cervical cancer

\footnotetext{
* Correspondence: edochomo@gamil.com

${ }^{1}$ School of Public Health and Community Development, Maseno University,

Private Bag, Maseno, Kenya

Full list of author information is available at the end of the article
} 


\section{Background}

Globally, cervical cancer is the fourth most frequent cancer in women, with an estimated 530,000 new cases in 2012, representing $7.5 \%$ of all female cancer deaths. Of the estimated more than 270,000 deaths from cervical cancer every year, more than $85 \%$ of these occur in less developed regions. In developed countries, programmes are in place thnat enable women to be screened, making most pre-cancerous lesions identifiable at stages when they can easily be treated. Early treatment prevents up to $80 \%$ of cervical cancers in these countries [1]. In developing countries, cervical cancer is the second most common cancer, with an estimated 450,000 new cases in 2012 (84\% of the new cases worldwide) [2]. Furthermore, it was estimated that $95 \%$ of women in developing countries had never been screened for cervical cancer, mainly due to lack of awareness amongst the population [1]. This underscores the need for public education that is undertaken by the community health volunteers ( $\mathrm{CHVs}$ ) under the community strategy arrangement.

In sub-Saharan Africa, 34.8 new cases of cervical cancer are diagnosed per 100,000 women annually, and $22.5 / 100,000$ women die from the disease, making it the second most common cancer after breast cancer [3]. The disease burden is significantly higher in the developing countries with lower screening rates, largely due to lack of screening that allows for detection of a precancerous lesion and early stage cervical cancer. Data from hospital-based registries in Kenya indicated that cancer of the cervix accounts for $70-80 \%$ of all cancers of the genital tract [4]. Despite the magnitude of the problem in Kenya and the fact that it is easily preventable, cervical cancer screening coverage in Kenya for all women aged 18 to 69 years is only 3.2\% against a target of $70 \%$ coverage. In Kisumu County, only $2 \%$ of the women of reproductive age (WRA) were screened within the Kadibo Division, recording just a $1.5 \%$ screening rate in 2013 [5]. The Family AIDS Care and Education Services (FACES) programme, a local Non-Governmental Organization (NGO), was initiated and is supporting training and mentorship of healthcare workers in cervical cancer screening in various health facilities in Kisumu County [6], but the uptake of screening has been poor due to inadequate knowledge of the general population [7]. This trend requires public education to reverse and improve screening in order to identify those at risk of cervical cancer and to establish the prevalence of cervical cancer.

Furthermore, data from the 2014 Kenya Demographic and Health Survey (KDHS) indicates that only $14 \%$ of women aged 15-49 years have ever had a cervical exam [8]. The women, therefore, need to be enlightened about cervical cancer to create an enhanced need for screening.
Use of CHVs has been shown to be effective in passing health information [9]; however, their ability to create demand for the screening services depends largely on their ability to pass correct information to community members. Under the community strategy approach adopted by the ministry of health of Kenya in 2006, the CHVs carry out public education on health-related issues, including cervical cancer screening and prevention, and refer community members to health facilities for the services. The reporting tool (MOH 514) also requires them to report on the number of clients referred for cervical cancer screening among other health indicators. This means that the $\mathrm{CHVs}$ create demand for the cervical cancer screening services in the community after training; however, information of their knowledge about cervical cancer was lacking.

Enlightened women who have access to information about their health and are able to make informed decisions have been shown to be more likely to seek cervical cancer screening [10,11], while a high level of knowledge about cervical cancer was found to be a key predictor of screening intent [12]. To enhance cervical cancer screening and early detection, it is important that women access the most critical information, including the risk factors, signs and symptoms and where screening services can be accessed [13].

According to the World Health Organization (WHO), a risk factor is any attribute, characteristic or exposure of an individual that increases the likelihood of developing a disease or injury [1]. Some examples of the risk factors for cervical cancer are early onset of sexual activity, human papilloma virus (HPV) infection, smoking and immune suppression [14]. Prevention and control of disease and injury require information about the leading medical causes of illness and exposures or risk factors. This creates a focus on areas that can be changed or avoided rather than those that cannot be changed [15]. Those exposed to risk factors that cannot be changed can also seek early and regular check-ups. Knowledge about the risk factors is therefore a very important component of disease prevention and control. With the right information, the community members will be able to determine whether they are at risk or not and hence seek cervical cancer screening services accordingly. In Kadibo Division, even though information about the risk factors of cervical cancer is easily available to $\mathrm{CHVs}$, information about the knowledge of risk factors of cervical cancer in women of reproductive age was lacking amongst them. As such, the current study assessed the knowledge among the community health volunteers of the risk factors associated with cervical cancer in Kadibo Division, Kisumu County, Kenya.

Disease manifestation is very important in its diagnosis, management and treatment [16]; therefore, health 
service providers must know the right signs and symptoms to look for in order to give the right and timely medical attention to any disease and curb the development and spread of the disease. The right information can also be passed to the public to enable them seek timely medical attention on noticing such signs [17-19]. The most appropriate channel to pass this information is through the community gatekeepers, the CHVs. Having the right information regarding signs and symptoms of cervical cancer in the community creates demand for the available screening services at the health facilities and enhances screening to establish the cervical cancer prevalence rate. The information regarding knowledge of the signs and symptoms of cervical cancer among community health volunteers in Kadibo Division, Kisumu County remains undetermined. Therefore, the current study set out to assess the knowledge of the signs and symptoms of cervical cancer among community health volunteers in Kadibo Division, Kisumu County.

The knowledge about the availability of medical services determines how the society embraces and utilizes such services [20]. It is important to have medical services available and accessible to the community in order to promote prevention, management and cure of medical conditions [21]. An informed community will create demand for the available screening services and in turn enable establishment of cervical cancer prevalence rate. This information on the available screening services, cost and duration of screening is usually passed to the community members by the CHVs. However, the information on the CHVs' knowledge of the availability of cervical cancer screening services in Kadibo Division, Kisumu County remains unknown. As such, the current study assessed the knowledge of the availability of cervical cancer screening services among community health volunteers in Kadibo Division, Kisumu County.

Finally, the knowledge of an individual is influenced by various factors that act as a system of various specific issues to have a net effect on an individual's general knowledge. These factors are collectively denoted as sociodemographic factors and include indicators such as gender, age, education level, religion, marital status and occupation. The effect of these socio-demographic factors on the knowledge of the $\mathrm{CHVs}$ about cervical cancer screening remained unknown in Kadibo Division, Kisumu County. As such, the current study determined the socio-demographic factors influencing the knowledge of the CHVs of cervical cancer.

\section{Method}

\section{Study site}

The study was carried out in Kadibo Division, Kisumu County, which lies between latitudes -0.1959 and longitudes 34.8590 (Fig. 1: Study location). Kadibo has four government health facilities: namely, Rabuor, Nyangande, Kanyagwal and Hongo Ogosa. All these facilities offer maternal and child health services among other medical services. Each facility has community units attached to it, with each unit having $10 \mathrm{CHVs}$ serving the households. The study site is in Nyando Sub-County,

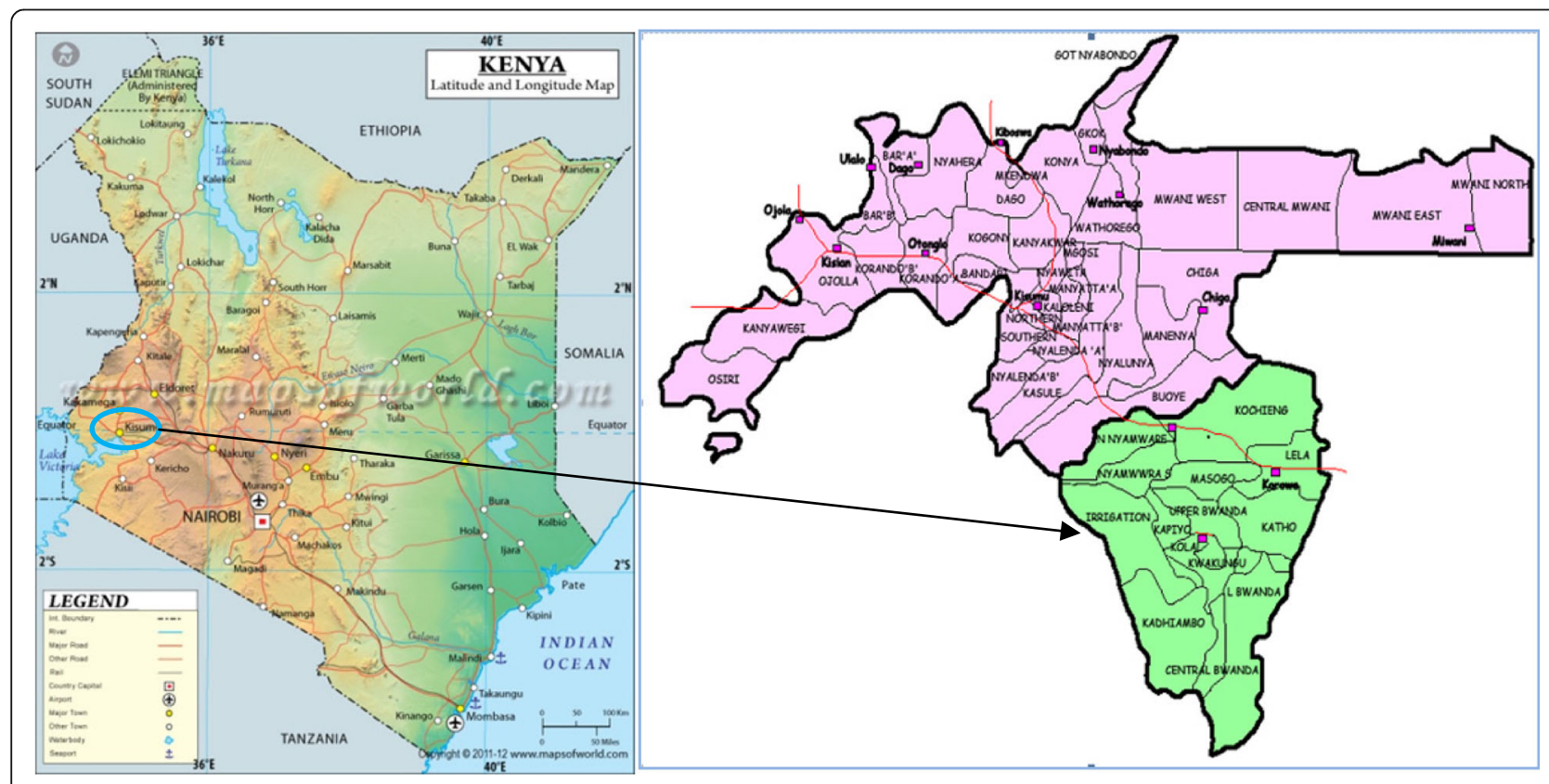

Fig. 1 This is the map of the study site in Kadibo Division, Nyando Sub-County, Kisumu County, Kenya. It is served by four health centres, offering maternal and reproductive health services 
where, according to District Health Information Systems (DHIS) 2015, sexually transmitted infections accounted for $45.4 \%$ of the total cases attending special clinics in 2015. The prevalence of cervical cancer, however, remains unknown due to low screening rates, with only opportunistic screening being observed at the health facilities. The study site, though, boasts functioning community units with active CHVs, which made it ideal for this study.

\section{Target population}

The targeted population was the registered $\mathrm{CHVs}$ attached to the government health facilities in Kadibo Division, Kisumu County. Their number, according to DHIS 2015 and the facility records, was 188 . This was distributed as follows: 50 in Rabuor, 89 in Nyangande, 19 in Kanyagwal and 30 in Hongo Ogosa. All these CHVs were included in the current study.

\section{Study design}

This was a cross-sectional saturated study in which all the 188 registered $\mathrm{CHVs}$ were interviewed about their knowledge regarding the risk factors, signs and symptoms and the availability of cervical cancer screening services. Since the required information could be collected through a one-time interview, the questionnaires for this study were administered to the CHVs only once.

\section{Sample size determination, sampling techniques and research instruments}

Saturated sampling was done; therefore, all the targeted $188 \mathrm{CHVs}$ were included in the study. The research instrument used was a semi-structured questionnaire.

\section{Data collection techniques}

After obtaining written informed consent, data were collected through administration of the questionnaires to the study participants by trained research assistants.

\section{Data processing, presentation and analysis}

Filled questionnaires were checked for completeness and correctness and then tallied and entered into an Excel spreadsheet before being exported to Statistical Package for Social Sciences (SPSS) for analysis. Participants' demographic characteristics were presented by use of median and inter-quartile range for continuous variables and proportions and frequencies for categorical variables. Knowledge about cervical cancer was categorized based on percentage scores. There were three ordered categories of knowledge: low knowledge, average knowledge and high knowledge. Knowledge about signs and symptoms of cervical cancer was presented by use of frequencies and proportions. The knowledge about screening services at health facilities was presented by use of proportions. Chi-square testing was used to determine which demographic characteristics were important in determining the knowledge. $P \leq 0.05$ were considered statistically significant.

\section{Ethical approval}

The authority to carry out the study was obtained from the Maseno University's School of Graduate Studies (SGS). Ethical approval was granted by the Maseno University Ethics Review Committee (MUERC) before recruitment into the study; the participants' written informed consent was also sought. The authority of the Kisumu County Health Management was also obtained at the county, sub-county and facility levels. Lastly, the confidentiality of the information and the anonymity of the participants were guaranteed.

\section{Results}

\section{Demographic characteristics of participants}

The majority of the participants 161 (85.6\%) were women, with only 27 (14.4\%) being men. The distribution according to age was as follows: 3 for 20-24 years (1.6\%), 13 for $25-29$ years (6.9\%), 30 for $30-34$ years (16.0\%), 26 for $35-39$ years (13.8\%), 37 for $40-44$ years (19.7\%), 30 for $45-49$ years $(16.0 \%), 26$ for $50-54$ years (13.8\%), 13 for $55-59$ years (6.9\%) and 10 for $60-64$ years (5.3\%). A majority at $91(48.4 \%)$ had a primary level of education, while $85(45.2 \%)$ had a secondary level of education and only $12(6.4 \%)$ respondents had a postsecondary level of education. All the 188 (100\%) respondents were Christians. The majority of the respondents 168 (89.4\%) were married, whereas 18 (9.6\%) did not have spouses anymore (divorced, separated or widowed) with only $2(1.1 \%)$ saying that they were single/never married. A majority of 132 (70.2\%) were small-scale farmers, followed by $24(12.8 \%)$ who were in business, $21(11.2 \%)$ were manual labourers and 11 (5.9\%) engaged in commercial farming. The respondents were able to indicate the duration over which they had worked as CHVs; a majority of the respondents, 91 (48.4\%) in total, had worked for over 7 years, 70 (37.2\%) had worked for 5-7 years, 24 (12.8\%) had worked between 2 and 4 years and $3(1.6 \%)$ had worked for less than 2 years, as presented in Table 1.

\section{Knowledge about the risk factors associated with cervical cancer}

The respondents were asked to list the risk factors associated with cervical cancer; they were allowed to give multiple responses that were then scored, and proportions were worked out given the number of risk factors that a respondent was able to list.

All $188(100 \%)$ respondents indicated that they had heard about cervical cancer and correctly indicated that 
Table 1 Demographic Characteristics of the Study Participants

\begin{tabular}{|c|c|c|}
\hline \multicolumn{2}{|c|}{ Respondent characteristics } & \multirow{2}{*}{$\frac{\text { Number of respondents }}{27(14.4 \%)}$} \\
\hline Gender & Male & \\
\hline & Female & $161(85.6 \%)$ \\
\hline \multirow[t]{9}{*}{ Age (Years) } & $20-24$ & $3(1.6 \%)$ \\
\hline & $25-29$ & $13(6.9 \%)$ \\
\hline & $30-34$ & $30(16.0 \%)$ \\
\hline & $35-39$ & $26(13.8 \%)$ \\
\hline & $40-44$ & $37(19.7 \%)$ \\
\hline & $45-49$ & $30(16.0 \%)$ \\
\hline & $50-54$ & $26(13.8 \%)$ \\
\hline & $55-59$ & $13(6.9 \%)$ \\
\hline & $60-64$ & $10(5.3 \%)$ \\
\hline \multirow[t]{3}{*}{ Education level } & Primary & $91(48.4 \%)$ \\
\hline & Secondary & $85(45.2 \%)$ \\
\hline & Post-secondary & $12(6.4 \%)$ \\
\hline Religion & Christian & 188(100\%) \\
\hline \multirow[t]{3}{*}{ Marital status } & Single & $2(1.1 \%)$ \\
\hline & Married & 168(89.4\%) \\
\hline & Separated & 18(9.6\%) \\
\hline \multirow[t]{4}{*}{ Occupation } & Small scale farming & $132(70.2 \%)$ \\
\hline & Commercial farming & $11(5.9 \%)$ \\
\hline & Business & $24(12.8 \%)$ \\
\hline & Casual laborer & $21(11.2 \%)$ \\
\hline \multirow[t]{4}{*}{ Facility of attachment } & Rabuor & $50(26.6 \%)$ \\
\hline & Nyangande & $89(47.3 \%)$ \\
\hline & Hongo Ogosa & $30(16.0 \%)$ \\
\hline & Kanyagwal & 19(10.1\%) \\
\hline \multirow[t]{4}{*}{ Years of service } & $<2$ & $3(1.6 \%)$ \\
\hline & $2-4$ & $24(12.8 \%)$ \\
\hline & $5-7$ & $70(37.2 \%)$ \\
\hline & $>7$ & $91(48.4 \%)$ \\
\hline
\end{tabular}

Data are numbers (proportions)

it affected women. It was established that the majority of the respondents at $128(68.1 \%)$ had low knowledge of risk factors associated with cervical cancer, with only 60
(31.9\%) recording average knowledge and none having high knowledge, as shown in Table 2. The mean score for the participants was calculated as $30.83 \%$ [minimum $0.00 \%$, maximum $66.67 \%$; standard deviation $(\mathrm{SD})=0.897$, which was interpreted as having a generally low knowledge of risk factors associated with cervical cancer. The difference in the distributions of knowledge across the different categories was significant $(p<0.0001)$.

Having many sexual partners was identified by 130 (69.1\%) respondents, HPV infection was identified by 100 (53.2\%), and early onset of sexual activity was identified by 99 (52.7\%). Immune suppression in 179 (95.2\%), having many children in 181 (96.3\%) and smoking in 185 (98.4\%) were identified as non-risk factors for cervical cancer, as shown in Table 2.

The general knowledge about the risk factors associated with cervical cancer was affected by the level of education at $\left(p=0.012, x^{2}=3.839\right)$, occupation $\left(p<0.0001, x^{2}=12.722\right)$, and health centre of attachment $\left(p<0.0001, \chi^{2}=71.013\right)$. However, regression analyses showed that only the health facility of attachment was important in determining knowledge on risk factors associated with cervical cancer. For example, CHVs attached to Rabour were 70 times more likely to be knowledgeable [Odds Ratio (OR) $=70.200,95 \%$ Confidence Interval $(\mathrm{CI})=8.341-590.809, p<0.0001]$ relative to other areas (Table 3).

\section{Knowledge about the signs and symptoms of cervical cancer}

The respondents were asked to list the signs and symptoms that are suggestive of cervical cancer, while allowing for multiple responses. The results were scored and proportions presented. Approximately 95 (50.5\%) had low knowledge, 15 (8.0\%) had average knowledge, and $78(41.5 \%)$ had high knowledge. The mean score of the study participants was calculated as $58.75 \%$ (minimum $0 \%$, maximum $100 \%, \mathrm{SD}=1.285)$. This was interpreted as average knowledge about signs and symptoms of cervical cancer amongst the CHVs. The difference in the distributions of the knowledge across the different categories was significant $(p<0.0001)$.

Table 2 Knowledge about the Risk Factors Associated With Cervical Cancer

\begin{tabular}{|c|c|c|c|c|c|c|}
\hline & Many children & Many sexual partners & Early onset of sexual activity & HPV infection & Smoking & Immune suppression \\
\hline Yes & $7(3.7 \%)$ & $130(69.1 \%)$ & $99(52.7 \%)$ & $100(53.2 \%)$ & $3(1.6 \%)$ & $9(4.8 \%)$ \\
\hline No & $181(96.3 \%)$ & $58(30.9 \%)$ & $89(47.3 \%)$ & $88(46.8 \%)$ & 185(98.4\%) & 179(95.2\%) \\
\hline \multirow[t]{3}{*}{ Total } & 188(100\%) & 188(100\%) & 188(100\%) & 188(100\%) & 188(100\%) & 188(100\%) \\
\hline & & \multicolumn{5}{|c|}{ Knowledge About Risk Factors } \\
\hline & & Low & Average & High & & \\
\hline \multicolumn{2}{|c|}{ Knowledge on risk factors } & $128(68.1 \%)$ & 60(31.9\%) & $0(0.0 \%)$ & & \\
\hline
\end{tabular}

Data are in numbers (percentage). Knowledge categories are based on the number of risk factors identified out of the six, converted to percentage then stratified as low, average and high knowledge 
Table 3 Relationship between Demographic Factors and Knowledge of Risk Factors Associated With Cervical Cancer

\begin{tabular}{|c|c|c|c|c|c|c|c|}
\hline $\begin{array}{l}\text { Demographic } \\
\text { characteristic }\end{array}$ & Df & $\begin{array}{l}\text { Many children } \\
\text { ( } p \text {-value) }\end{array}$ & $\begin{array}{l}\text { Many sexual } \\
\text { partners (p-value) }\end{array}$ & $\begin{array}{l}\text { Early onset of sexual activity } \\
\text { ( } p \text {-value) }\end{array}$ & $\begin{array}{l}\text { HPV infection } \\
\text { (p-value) }\end{array}$ & $\begin{array}{l}\text { Smoking } \\
\text { ( } p \text {-value) }\end{array}$ & $\begin{array}{l}\text { Immune suppression } \\
\text { (p-value) }\end{array}$ \\
\hline Gender & 1 & 0.269 & 0.229 & 0.356 & 0.272 & 0.475 & 0.096 \\
\hline Age & 8 & 0.148 & 0.003 & 0.290 & 0.650 & 0.411 & 0.292 \\
\hline Education & 2 & 0.465 & 0.517 & 0.728 & 0.310 & 0.800 & 0.001 \\
\hline Marital status & 2 & 0.214 & 0.337 & 0.965 & 0.313 & 0.367 & 0.940 \\
\hline Occupation & 3 & 0.093 & 0.008 & $<0.0001$ & 0.270 & 0.374 & 0.617 \\
\hline Health centre & 3 & 0.399 & $<0.0001$ & $<0.0001$ & $<0.0001$ & 0.584 & 0.001 \\
\hline $\begin{array}{l}\text { Duration } \\
\text { worked }\end{array}$ & 3 & 0.177 & 0.386 & 0.065 & 0.060 & 0.355 & 0.114 \\
\hline \multirow{2}{*}{\multicolumn{2}{|c|}{ Demographic characteristics }} & Proportions & $\begin{array}{l}\text { Knowledge on risk } \\
\text { factors ( } p \text { value) }\end{array}$ & $\begin{array}{l}\text { Knowledge on risk factors } \\
\left(x^{2} \text { values }\right)\end{array}$ & \multicolumn{3}{|c|}{ Logistic regression } \\
\hline & & & & & $p$-value & \multicolumn{2}{|c|}{ O.R. $(95 \% \mathrm{Cl})$} \\
\hline Gender & $\begin{array}{l}\text { Male } \\
\text { Female }\left(\operatorname{Ref}^{*}\right)\end{array}$ & $N A^{*}$ & 0.929 & 0.520 & 0.472 & \multicolumn{2}{|c|}{$1.402,(0.558-3.523)$} \\
\hline \multirow[t]{9}{*}{ Age groups } & & & & & 0.089 & & \\
\hline & $20-24$ & $N A^{*}$ & 0.142 & 5.518 & 0.287 & \multicolumn{2}{|c|}{$0.167,(0.006-4.515)$} \\
\hline & $25-29$ & & & & 0.022 & \multicolumn{2}{|c|}{$0.050,(0.004-0.652)$} \\
\hline & $30-34$ & & & & 0.162 & \multicolumn{2}{|c|}{$0.183,(0.017-1.980)$} \\
\hline & $35-39$ & & & & 0.121 & \multicolumn{2}{|c|}{$0.155,(0.015-1.634)$} \\
\hline & $40-44$ & & & & 0.071 & \multicolumn{2}{|c|}{$0.111,(0.010-1.207)$} \\
\hline & $45-49$ & & & & 0.103 & \multicolumn{2}{|c|}{$0.136,(0.012-1.492)$} \\
\hline & $50-54$ & & & & 0.531 & \multicolumn{2}{|c|}{$0.458,(0.040-5.256)$} \\
\hline & $55-59\left(\operatorname{Ref}^{*}\right)$ & & & & & & \\
\hline \multirow[t]{4}{*}{ Education level } & & & & & 0.150 & & \\
\hline & Primary, & $38.5 \%$ & 0.012 & 3.839 & 0.731 & \multicolumn{2}{|c|}{$1.250,(0.350-4.462)$} \\
\hline & Secondary, & $24.7 \%$ & & & 0.525 & \multicolumn{2}{|c|}{$0.656,(0.179-2.402)$} \\
\hline & $\begin{array}{l}\text { Post } \\
\text { secondary } \\
\text { (Ref*) }\end{array}$ & $33.3 \%$ & & & & & \\
\hline \multirow[t]{4}{*}{ Marital status } & & & & & 0.418 & & \\
\hline & Single & $N A^{*}$ & 0.059 & 1.789 & 0.881 & \multicolumn{2}{|c|}{$1.250,(0.067-23.259)$} \\
\hline & Married & & & & 0.228 & \multicolumn{2}{|c|}{$0.545,(0.203-1.461)$} \\
\hline & $\begin{array}{l}\text { Separated } \\
(\text { Ref*) }\end{array}$ & & & & & & \\
\hline \multirow[t]{5}{*}{ Occupation } & & & & & 0.086 & & \\
\hline & Small scale, & $39.4 \%$ & $<0.0001$ & 12.722 & 0.082 & \multicolumn{2}{|c|}{$2.763,(0.880-8.670)$} \\
\hline & $\begin{array}{l}\text { Commercial } \\
\text { farming }\end{array}$ & $0.0 \%$ & & & 0.999 & \multicolumn{2}{|l|}{0.000} \\
\hline & Business, & $16.7 \%$ & & & 0.835 & \multicolumn{2}{|c|}{$0.850,(0.184-3.923)$} \\
\hline & $\begin{array}{l}\text { Casual work } \\
\left(\operatorname{Ref}^{*}\right)\end{array}$ & $19.0 \%$ & & & & & \\
\hline \multirow{5}{*}{$\begin{array}{l}\text { Health centre } \\
\text { attached }\end{array}$} & & & & & $<0.0001$ & & \\
\hline & Rabuor & $80.0 \%$ & $<0.0001$ & 71.013 & $<0.0001$ & \multicolumn{2}{|c|}{$70.200,(8.341-590.809)$} \\
\hline & Nyangande & $16.9 \%$ & & & 0.181 & \multicolumn{2}{|c|}{$4.135,(0.516-33.150)$} \\
\hline & $\begin{array}{l}\text { Hongo } \\
\text { Ogosa }\end{array}$ & $13.3 \%$ & & & 0.541 & \multicolumn{2}{|c|}{$2.077,(0.200-21.596)$} \\
\hline & $\begin{array}{l}\text { Kanyagwal } \\
\left(\text { Ref*) }^{*}\right.\end{array}$ & $5.3 \%$ & & & & & \\
\hline
\end{tabular}


Table 3 Relationship between Demographic Factors and Knowledge of Risk Factors Associated With Cervical Cancer (Continued)

\begin{tabular}{|c|c|c|c|c|c|c|}
\hline \multirow{5}{*}{$\begin{array}{l}\text { Duration } \\
\text { worked in years }\end{array}$} & & \multirow{4}{*}{$N A^{*}$} & \multirow{4}{*}{0.059} & \multirow{4}{*}{1.581} & \multicolumn{2}{|l|}{0.673} \\
\hline & $<2$ & & & & 0.979 & $0.968,(0.084-11.095)$ \\
\hline & $2-4$ & & & & 0.219 & $0.509,(0.174-1.494)$ \\
\hline & $5-7$ & & & & 0.872 & $0.947,(0.489-1.834)$ \\
\hline & $>7(R$ & & & & & \\
\hline
\end{tabular}

Statistical significance determined by Chi-square and logistic regression analysis. Values in bold are statistically significant at $P \leq 0.05$. Proportion represents participants with average knowledge. NA* not applicable. Ref* Reference

A majority of the respondents mentioned the following as the signs and symptoms of cervical cancer: abnormal vaginal bleeding by 114 (60.6\%) respondents, abnormal vaginal discharge by 115 (61.2\%) respondents, abdominal pain by $99(52.7 \%)$ respondents and pain during sexual intercourse by 90 (47.9\%) respondents. The results are shown in Table 4.

Chi-square test results showed that there was no relationship between knowledge about signs and symptoms of cervical cancer and gender, age, education, marital status and the health centre of attachment of the respondent $\mathrm{CHVs}$. Nonetheless, the occupation of the respondent was found to be significantly related to the knowledge of whether abdominal pain $(p=0.002)$ and pain during sex $(p=0.003)$ were signs and symptoms of cervical cancer, while years of work as a CHV was significantly related to knowledge of abnormal vaginal discharge as a sign or symptom of cervical cancer $(p=0.003)$.

Finally, the overall knowledge about the signs and symptoms of cervical cancer were determined by the occupation of the CHVs $\left(p=0.030, \chi^{2}=15.110\right)$ and the years of work as a CHV $\left(p=0.014, \chi^{2}=8.451\right)$, as shown in Table 5.

\section{Knowledge about the availability of screening services at the health facilities}

The respondents answered questions on the various aspects of screening services offered at the health facilities with regards to the methods used, cost, the turn-around time and the rescreening interval. The proportion score for each respondent was determined and used to stratify their knowledge into the three categories. A majority at
77 (41.0\%) had high knowledge, followed by low knowledge in $71(37.8 \%)$, while 40 (21.2\%) had average knowledge (Table 6). The mean score was found to be $59.27 \%$ (minimum 0\%, maximum $86.67 \%$, SD =0.612). This was interpreted as average knowledge by the CHVs of the screening services for cervical cancer. The difference in the distributions of the knowledge was statistically significant $(p<0.0001)$.

Gender was significant in determining the knowledge about the cost of screening $(p=0.004)$, while age was important in determining knowledge on use of VILI as a screening method (0.003) and the TAT $(p=0.008)$. Education level was important in determining knowledge on use of VILI $(p=0.035)$ and VIA $(p=0.007)$ while occupation was significant in determining the knowledge about use of VIA $(p=0.004)$ and VILI $(p=0.008)$ and the TAT $(p=0.050)$. Finally, the health centre of attachment was important in determining knowledge about the use of VIA $(p=0.000)$ and VILI $(p=0.000)$, the cost of screening $(p=0.001)$, TAT $(p=0.001)$ and the frequency of screening $(p=0.000)$ while the duration of work was significant in determining the knowledge about use of VIA $(p=0.014)$, the cost of screening ( $p=$ $0.000)$, TAT $(p=0.018)$ and the frequency of screening $(p=0.003)$.

Education $(p=0.011)$ occupation $(p=0.002)$ and health centre of attachment $(p<0.0001)$ were significant in determining the knowledge levels on availability of screening services at the various health facilities. This is shown in Table 7.

It was further established that all 188 (100.0\%) of the respondents knew that screening services were

Table 4 Knowledge about the Signs and Symptoms of Cervical Cancer

\begin{tabular}{|c|c|c|c|c|}
\hline & Abnormal vaginal bleeding & Abnormal vaginal discharge & Abdominal pains & Pain during sexual intercourse \\
\hline Yes & $114(60.6 \%)$ & $115(61.2 \%)$ & $99(52.7 \%)$ & $90(47.9 \%)$ \\
\hline No & 74(39.4\%) & $73(38.8 \%)$ & $89(47.3 \%)$ & $98(52.1 \%)$ \\
\hline \multirow[t]{3}{*}{ Total } & 188(100\%) & 188(100\%) & 188(100\%) & 188(100\%) \\
\hline & & \multicolumn{3}{|c|}{ Knowledge About Signs and Symptoms } \\
\hline & & Low & Average & High \\
\hline \multicolumn{2}{|c|}{ Knowledge on signs and symptoms } & $95(50.5 \%)$ & 15(8.0\%) & $78(41.5 \%)$ \\
\hline
\end{tabular}

Data are in numbers (proportions). Knowledge categorized based on the number of signs and symptoms identified out of the four, converted to percentage then stratified into low, average and high knowledge 
Table 5 Relationship between Demographic Factors and Knowledge of Signs and Symptoms of Cervical Cancer

\begin{tabular}{|c|c|c|c|c|c|}
\hline $\begin{array}{l}\text { Demographic } \\
\text { characteristics }\end{array}$ & $d f$ & $\begin{array}{l}\text { Abnormal vaginal } \\
\text { bleeding ( } p \text {-value) }\end{array}$ & $\begin{array}{l}\text { Abnormal vaginal discharge } \\
\text { ( } p \text {-value) }\end{array}$ & $\begin{array}{l}\text { Abdominal } \\
\text { pains ( } p \text {-value) }\end{array}$ & $\begin{array}{l}\text { Pain during sex } \\
\text { (p-value) }\end{array}$ \\
\hline Gender & 1 & 0.353 & 0.263 & 0.283 & 0.423 \\
\hline Age & 8 & 0.189 & 0.787 & 0.035 & 1.114 \\
\hline Education & 2 & 0.130 & 0.547 & 0.907 & 0.429 \\
\hline Marital status & 2 & 0.824 & 0.203 & 0.292 & 0.495 \\
\hline Occupation & 3 & 0.075 & 0.243 & 0.002 & 0.003 \\
\hline $\begin{array}{l}\text { Health centre } \\
\text { attached }\end{array}$ & 1 & 0.263 & 0.283 & 0.928 & 0.423 \\
\hline Duration worked & 3 & 0.725 & 0.030 & 0.941 & 0.915 \\
\hline \multicolumn{2}{|c|}{ Demographic characteristics } & Proportions & $\begin{array}{l}\text { Knowledge on signs and } \\
\text { symptoms ( } p \text { value) }\end{array}$ & \multicolumn{2}{|c|}{$\begin{array}{l}\text { Knowledge on signs and } \\
\left.\text { symptoms ( } x^{2} \text { values }\right)\end{array}$} \\
\hline Gender & Male, Female & $N A^{*}$ & 0.263 & \multicolumn{2}{|l|}{0.171} \\
\hline Age & $\begin{array}{l}20-24,25-29,30-34,35-39,40-44,45- \\
49,50-54,55-59,60-64\end{array}$ & $N A^{*}$ & 0.239 & \multicolumn{2}{|l|}{14.175} \\
\hline Education & Primary, Secondary, Post secondary & $N A^{*}$ & 0.446 & \multicolumn{2}{|l|}{9.140} \\
\hline Marital status & Single, Married, Separated & $N A^{*}$ & 0.332 & \multicolumn{2}{|l|}{1.783} \\
\hline Occupation & $\begin{array}{l}\text { Small scale, Commercial farming, } \\
\text { Business, } \\
\text { Casual work }\end{array}$ & $\begin{array}{l}51.5 \% \\
9.1 \% \\
29.2 \% \\
28.6 \%\end{array}$ & 0.030 & \multicolumn{2}{|l|}{15.110} \\
\hline $\begin{array}{l}\text { Health centre } \\
\text { attached }\end{array}$ & $\begin{array}{l}\text { Rabuor, Nyangande, Hongo ogosa, } \\
\text { Kanyagwal }\end{array}$ & $N A^{*}$ & 0.060 & \multicolumn{2}{|l|}{86.472} \\
\hline $\begin{array}{l}\text { Duration worked } \\
\text { in years }\end{array}$ & $\begin{array}{l}<2 \\
2-4 \\
5-7 \\
>7\end{array}$ & $\begin{array}{l}0.0 \% \\
41.7 \% \\
45.7 \% \\
44.4 \%\end{array}$ & 0.014 & \multicolumn{2}{|l|}{8.451} \\
\hline
\end{tabular}

Statistical significance determined by Chi-square analysis. Values in bold are statistically significant at $P \leq 0.05$. Proportion represents participants with high knowledge. NA* not applicable

available at the health facilities where they were attached; however, they did not have the right information with respect to the screening methods used, with only $40(21.3 \%)$ and $37(19.7 \%)$ respondents correctly identifying visual inspection using acetic acid (VIA) and visual inspection using Lugol's iodine (VILI) as the methods being used, respectively. A majority of 174 (92.6\%) correctly mentioned that the services were being offered free of charge; however, the turnaround time for the screening tests and the re-testing interval were only known by $69(36.7 \%)$ and $3(1.6 \%)$, respectively (Table 6).

\section{Socio-demographic factors affecting knowledge about cervical cancer}

The knowledge about the risk factors associated with cervical cancer was determined by education $(p=0.012$, $\left.\chi^{2}=3.839\right)$, occupation $\left(p<0.0001, \chi^{2}=12.722\right)$, and health centre of attachment $\left(p<0.0001, X^{2}=71.013\right)$. However, the knowledge of the signs and symptoms of cervical cancer was determined by the occupation of the CHVs $\left(p=0.030, X^{2}=15.110\right)$ and the years of work as a $\operatorname{CHV}\left(p=0.014, X^{2}=8.451\right)$, while education $\left(p=0.011, \quad x^{2}=8.605\right)$, occupation $(p=0.002$, $\left.X^{2}=18.335\right)$ and health centre of attachment $\left(p<0.0001, x^{2}=101.705\right)$ were significant in determining the knowledge of availability of screening services at the various health facilities.

\section{Discussion}

\section{Knowledge of the risk factors associated with cervical} cancer

This study generally established that there was low knowledge of the risk factors of cervical cancer. This was in agreement with the findings of other studies [14] that established that Vietnamese American women were unable to correctly identify the cervical cancer risk factors. Another study [22] in Uganda noted that the knowledge level among medical workers was low at less than $40 \%$, while another [23] determined that the awareness of human papillomavirus (HPV) as a risk factor for cervical cancer was at a very low proportion of $2.5 \%$. In addition, other studies [24, 25] also demonstrated low knowledge of risk factors amongst the women in Wielkopolska region and Ethiopian health care workers. 
Table 6 Knowledge about the Availability of Screening Services at the Health Facilities

\begin{tabular}{|c|c|c|c|}
\hline \multicolumn{3}{|l|}{ Screening services components } & Respondents \\
\hline \multirow[t]{4}{*}{ Screening methods used } & \multicolumn{2}{|l|}{ VIA } & $40(21.3 \%)$ \\
\hline & \multicolumn{2}{|l|}{ VILI } & $37(19.7 \%)$ \\
\hline & \multicolumn{2}{|l|}{ Pap smear } & 72(38.3\%) \\
\hline & \multicolumn{2}{|l|}{ HPV testing } & $39(20.7 \%)$ \\
\hline \multirow[t]{3}{*}{ Cost } & \multicolumn{2}{|l|}{ Free } & 174(92.6\%) \\
\hline & \multicolumn{2}{|l|}{$<$ Ksh. 100} & $3(1.6 \%)$ \\
\hline & \multicolumn{2}{|l|}{ >Ksh. 100} & $11(5.9 \%)$ \\
\hline \multirow[t]{3}{*}{ Turn-around time } & \multicolumn{2}{|l|}{$<30$ Min. } & $69(36.7 \%)$ \\
\hline & \multicolumn{2}{|l|}{ 30-60 Min } & $112(59.6 \%)$ \\
\hline & \multicolumn{2}{|l|}{$>60 \mathrm{Min}$} & $6(3.7 \%)$ \\
\hline \multirow[t]{6}{*}{ Retesting interval } & \multicolumn{2}{|l|}{ Semi-annually } & $92(48.9 \%)$ \\
\hline & \multicolumn{2}{|l|}{ Annually } & $90(47.9 \%)$ \\
\hline & \multicolumn{2}{|l|}{ Every 5 years } & $3(1.6 \%)$ \\
\hline & \multicolumn{2}{|l|}{ Over 5 years } & $3(1.6 \%)$ \\
\hline & \multicolumn{3}{|c|}{ Knowledge category } \\
\hline & Low & Average & High \\
\hline Knowledge on the availability of screening services & $71(37.8 \%)$ & $40(21.2 \%)$ & $77(41.0 \%)$ \\
\hline
\end{tabular}

Data are in numbers (percentage). Knowledge categorized based on the amount of details about the screening services given, converted to percentage then stratified into low, average and high knowledge

This low knowledge can be attributed to the generally low education levels, which also have a bearing on the occupation of the CHVs. Lack of uniform training for the CHVs on the risk factors associated with cervical cancer and the fact that cervical cancer screening has also been neglected even though it is an important component of maternal health also contributed to the low knowledge. There is a need, therefore, to teach $\mathrm{CHVs}$ the risk factors of cervical cancer, since through them, the information can be passed to the community.

\section{Knowledge on the Signs and Symptoms of Cervical Cancer}

There was great disparity in the knowledge about the signs and symptoms, with an average of 95 (50.5\%) having low knowledge while 78 (41.5\%) had high knowledge and only 15 (8.0\%) had average knowledge.

These findings diverge with those from earlier studies [26] that pointed to low knowledge of warning signs/ symptoms of cervical cancer amongst study participants in the upper mid-western states. One study [27] established that the knowledge of the signs and symptoms of cervical cancer was as low as $6.3 \%$ amongst participants in North Bengal, India, while another study [28] observed a lack of knowledge of the signs and symptoms of cervical cancer amongst students at a medical school in Al-Ahsa, Kingdom of Saudi Arabia.

The average knowledge observed could be due to the ongoing sensitization in the audio-visual media, which mainly focuses on passing of information on the signs and symptoms to look out for but neglects other aspects. However, the disparity between the high and low knowledge needs to be investigated.

\section{Knowledge of the availability of screening services}

The knowledge of the details of the screening services ranged from low to high, with 71 (37.8\%) of the respondents having low, $40(21.2 \%)$ having average and 77 (41.0\%) having high knowledge.

It was established that only $40(21.3 \%)$ and $37(19.7 \%)$ of the respondents were able to correctly identify VIA and VILI as the screening methods available in the health facilities. A majority of 71 (37.8\%) wrongly identified Pap smear, followed by HPV testing by 40 (21.3\%), as being available in the health facilities. A majority of the respondents $(176(93.6 \%))$ across the health facilities mentioned that the screening services were available free of charge; $10(5.3 \%)$ of the respondents mentioned that the screening services cost more than Ksh.100, while a minority of $2(1.1 \%)$ indicated that the cost of screening was less than Ksh.100. The screening services take less than $30 \mathrm{~min}$, as correctly mentioned by $71(37.8 \%)$ of the respondents; however, a majority of 111 (59.0\%) thought the screening takes 30-60 min, while $6(2 \%)$ said that screening takes more than $60 \mathrm{~min}$. A majority of the respondents at $92(48.9 \%)$ said routine screening should be done semi-annually, and 90 (47.9\%) said annually, with only $3(1.6 \%)$ saying every 5 years and the same 
Table 7 Relationship between Demographic Characteristics and Knowledge about Availability of Screening Services

\begin{tabular}{|c|c|c|c|c|c|}
\hline Demographic characteristics & $\begin{array}{ll}\text { df } & \text { VIA } \\
& \text { (p-value) }\end{array}$ & $\begin{array}{l}\text { VILI } \\
\text { (p-value) }\end{array}$ & Cost of screening ( $p$-value) & $\begin{array}{l}\text { TAT } \\
(p \text {-value) }\end{array}$ & $\begin{array}{l}\text { Frequency of screening } \\
\text { ( } p \text {-value) }\end{array}$ \\
\hline Gender & 10.169 & 0.449 & 0.004 & 0.401 & 0.709 \\
\hline Age & $8 \quad 0.148$ & 0.003 & 0.820 & 0.008 & 0.604 \\
\hline Education & 20.035 & 0.007 & 0.494 & 0.402 & 0.374 \\
\hline Marital status & 20.324 & 0.447 & 0.253 & 0.161 & 0.984 \\
\hline Occupation & 30.004 & 0.008 & 0.088 & 0.050 & 0.108 \\
\hline Health centre attached & $1<0.0001$ & $<0.0001$ & 0.001 & 0.001 & $<0.0001$ \\
\hline Duration worked & 30.014 & 0.495 & $<0.0001$ & 0.018 & 0.003 \\
\hline Demographic characteristics & & Proportions & Knowledge on availability of screening services ( $p$ value) & \multicolumn{2}{|c|}{$\begin{array}{l}\text { Knowledge on availability of } \\
\text { screening services ( } x^{2} \text { values) }\end{array}$} \\
\hline Gender & $\begin{array}{l}\text { Male, } \\
\text { Female }\end{array}$ & $N A^{*}$ & 0.283 & \multicolumn{2}{|l|}{19.792} \\
\hline Age & $\begin{array}{l}20-24,25- \\
29,30-34 \\
35-39,40- \\
44,45-49 \\
50-54,55- \\
59,60-64\end{array}$ & $N A^{*}$ & 0.055 & \multicolumn{2}{|l|}{14.711} \\
\hline Education & $\begin{array}{l}\text { Primary, } \\
\text { Secondary, } \\
\text { Post } \\
\text { secondary }\end{array}$ & $\begin{array}{l}8.0 \% \\
7.4 \% \\
1.1 \%\end{array}$ & 0.011 & \multicolumn{2}{|l|}{8.605} \\
\hline Marital status & $\begin{array}{l}\text { Single, } \\
\text { Married, } \\
\text { Separated }\end{array}$ & $N A^{*}$ & 0.292 & \multicolumn{2}{|l|}{4.470} \\
\hline Occupation & $\begin{array}{l}\text { Small scale, } \\
\text { Commercial } \\
\text { farming, } \\
\text { Business, } \\
\text { Casual work }\end{array}$ & $\begin{array}{l}18.9 \% \\
0.0 \% \\
1.1 \% \\
19.0 \%\end{array}$ & 0.002 & \multicolumn{2}{|l|}{18.335} \\
\hline Health centre attached & $\begin{array}{l}\text { Rabuor, } \\
\text { Nyangande, } \\
\text { Hongo } \\
\text { ogosa, } \\
\text { Kanyagwal }\end{array}$ & $\begin{array}{l}28.0 \% \\
3.4 \% \\
13.3 \% \\
57.9 \%\end{array}$ & $<0.0001$ & \multicolumn{2}{|l|}{101.705} \\
\hline Duration worked in years & $\begin{array}{l}<2,2-4,5-7, \\
>7\end{array}$ & $N A^{*}$ & 0.271 & \multicolumn{2}{|l|}{6.558} \\
\hline
\end{tabular}

Statistical significance determined by Chi-square analysis. Values in bold are statistically significant at $P \leq 0.05$. Proportion represents participants with high knowledge. $N A^{*}$ not applicable

for after 5 years. In fact, routine screening should be once every five years.

It was evident that a majority of the $\mathrm{CHVs}$ were not aware of the screening methods available and the duration of screening. This was consistent with the findings of [29], where the purpose and importance of a Pap smear were not well understood amongst the high-risk women studied. Another study [30] established that 3\% of female health workers did not know about the availability of the services and therefore did not seek screening and were therefore likely to pass wrong information to the community. Furthermore, in previous studies [31-33], it was established that a lack of awareness of availability of screening centres locally, cost and time were the main reasons given by respondents for not being screened.
The low score on the knowledge of methods of screening, the duration of screening and retesting interval were found to be low due to lack of training for the CHVs on the details of the screening services available. However, the high score on cost can be explained by the fact that all the services at the government health centres and dispensaries are currently free of charge. There was a significant relationship between the centre a particular $\mathrm{CHV}$ is attached to and the screening method available in the facility ( $p$ 0.001).

The general knowledge was significantly related to education levels, which also influences occupation. These factors had a bearing on the kind of information a person vests their interest in. This average knowledge on availability of cervical cancer screening services is not sufficient for 
the gatekeeper role played by CHVs, and therefore, there is a need for their training and sensitization to pass accurate and consistent information to the community.

\section{Socio-demographic factors affecting the knowledge of cervical cancer}

Level of education $(p=0.012)$, occupation $(p<0.0001)$, and facility of attachment $(p<0.0001)$ were found to significantly affect knowledge about risk factors associated with cervical cancer. This was similar to previous findings [34-36] that observed level of education and occupation to significantly affect knowledge of cervical cancer. CHVs with just a primary level education had better knowledge about the risk factors associated with cervical cancer than those with higher education. This is an indication that the formal education does not give more information about cervical cancer risk factors; therefore, there is a need for more training of the CHVs. The CHVs involved in small-scale farming were also found to have better knowledge. Lack of uniform training for the CHVs through health talks and continuous medical education on the risk factors associated with cervical cancer in the various health facilities explains why the health facility of attachment was a significant determinant of the knowledge of CHVs about cervical cancer. Rabuor had the most consistent series of health talks, and this has an effect on the scores obtained by the CHVs attached to these centres.

Occupation $(p=0.030)$ and duration of service as a CHV ( $p=0.014)$ were found to be significant in determining the knowledge about signs and symptoms of cervical cancer as was also demonstrated in previous studies [25, 36, 37]. CHVs who practise small-scale farming were found to be more knowledgeable, similarly to those who had served for more than 5 years as $\mathrm{CHVs}$. With more years of service, the CHVs gain experience and more information from their interaction with the health care workers and within themselves.

The knowledge of availability of screening services was significantly related to the level of education ( $p=0.011)$, similar to previous findings $[38,39]$. The $\mathrm{CHVs}$ with post-secondary education were found to have better knowledge. This could allude to the complexity of the details of the screening methods that require more brain power to comprehend. Occupation $(p=0.002)$ was also significant in determining knowledge of availability of cervical cancer screening services. This was similar to earlier findings $[25,36,39]$, which also found occupation to significantly affect knowledge of cervical screening. Those CHVs practising small-scale farming and casual labourers were found to be more knowledgeable. Occupation generally has a bearing on the kind of information a person vests interest in. Finally, the health facility of attachment $(p<0.0001)$ was also significant in determining the knowledge about the availability of cervical cancer screening services in the respective health facilities. $\mathrm{CHVs}$ attached to Kanyagwal were also knowledgeable about screening services since because of their small number, they have more contact with the technical staff offering the services and thus better exposure to such information.

\section{Conclusions}

The community health volunteers had low knowledge of the risk factors associated with cervical cancer. There was notable misinformation among the $\mathrm{CHVs}$ as far as risk factors for cervical cancer are concerned. The CHVs had an average knowledge about the signs and symptoms of cervical cancer; however, some signs and symptoms were not known by the majority of the respondents. Being the community gatekeepers, average knowledge is not sufficient to pass to the community since it will result in misinformed populations. There is a need, therefore, to enlighten the CHVs on the signs and symptoms of cervical cancer. There was also average knowledge about the screening services that were available in the health facilities. The CHVs had inaccurate information with regard to the availability of the various screening methods at the facilities, how long it takes to have screening done and the rescreening interval. Lastly, the following were found to significantly influence the knowledge of CHVs about cervical cancer: level of education, occupation, health facility of attachment and years of service as a CHV.

\section{Abbreviations}

ACCP: Alliance for Cervical Cancer Prevention; AIDS: Acquired immunodeficiency syndrome; CCS: Cervical cancer screening; CHV: Community health volunteer; Cl: Confidence interval; DHIS: District health information systems; FACES: Family Aids Care and Educational Services; HIV: Human immunodeficiency virus; HPV: Human papillomavirus; IARC: International Agency for Research on Cancer; ICC: Invasive cervical cancer; KNH: Kenyatta National Hospital; NGO: Non-governmental organisation; OR: Odds ratio; SD: Standard deviation; SGS: School of graduate studies; STI: Sexually transmitted infection; TAT: Turn-around time; VIA: Visual inspection with acetic acid; VILI: Visual inspection using Lugol's lodine; WHO: World Health Organization; WRA: Women of Reproductive Age

\section{Acknowledgements}

Special thanks to the health department of the county government of Kisumu, especially Nyando Sub-County for its cooperation and support during my data collection, and finally to my data collection team and all the community health volunteers for their participation.

Funding

Not applicable.

Availability of data and materials

The data from which the study conclusions are drawn can be requested from the authors.

\section{Authors' contributions}

OEO designed and carried out the data collection in the field and participated in the drafting of the manuscript. HA, SG and CO made substantial contributions to the design and interpretation of the data. HA, SG and $\mathrm{CO}$ were also involved in revising the manuscript critically for important 
intellectual content. They also gave the final approval of the version to be published and have agreed to be accountable for all aspects of this work. All authors read and approved the final manuscript.

\section{Ethics approval and consent to participate}

The authority to carry out the study was obtained from the Maseno University's School of Graduate Studies (SGS). Ethical approval was granted by the Maseno University Ethics Review Committee (MUERC) and obtained before recruitment into the study; the participants' written informed consent was also sought. The authority of the Kisumu County Health Management was also obtained at the county, sub-county and facility levels. Lastly, the confidentially of the information and the anonymity of the participants were guaranteed. Access to data was limited to the principal investigator, and the data were kept in locked cabinets and in files protected with passwords to enhance confidentiality.

\section{Consent for publication}

Not applicable.

\section{Competing interests}

The authors declare that they have no competing interests.

\section{Publisher's Note}

Springer Nature remains neutral with regard to jurisdictional claims in published maps and institutional affiliations.

\section{Author details}

'School of Public Health and Community Development, Maseno University, Private Bag, Maseno, Kenya. ${ }^{2}$ School of Arts and Social Sciences, Maseno University, Private Bag, Maseno, Kenya. ${ }^{3}$ Ideal Research Center, P.O. Box 7244-40123, Kisumu, Kenya.

Received: 9 February 2017 Accepted: 4 September 2017

Published online: 25 September 2017

\section{References}

1. WHO Comprehensive cervical cancer control: a guide to essential practice.2006

2. WHO: Human Papilloma Virus (HPV) and Cervical Cancer: Fact Sheet. World Health Organization; 2016.

3. Ferlay J, Soerjomataram I, Dikshit R, Eser S, Mathers C, Rebelo M, Parkin DM, Forman D, Bray F. Cancer incidence and mortality worldwide: sources, methods and major patterns in GLOBOCAN 2012. Int J Cancer. 2012;136: E359-86.

4. GoK: DHIS web report. (Health ed.: DHIS2; 2015.

5. FACES: Kisumu District CCSP Data. KEMRI-FACES; 2014.

6. Huchko MJ, Bukusi EA, Cohen CR. Building capacity for cervical cancer screening in outpatient HIV clinics in the Nyanza province of western Kenya. Int J Gynaecol Obstet. 2011;114:106-10.

7. Rosser Jl, Hamisi S, Njoroge B, Huchko MJ. Barriers to Cervical Cancer Screening in Rural Kenya: Perspectives from a Provider Survey. I Community Health. 2015;40:756-61.

8. KNBS: 2014 KDHS Key Findings. (International Kal ed. pp. 17. Maryland:GoK 2015:17

9. Wangalwa G, Cudjoe B, Wamalwa D, Machira Y, Ofware P, Ndirangu M, llako F. Effectiveness of Kenya's Community Health Strategy in delivering community-based maternal and newborn health care in Busia County, Kenya: non-randomized pre-test post test study. Pan Afr Med J. 2012:13 Suppl 1:12.

10. Coronado Interis E, Anakwenze CP, Aung M, Jolly PE. Increasing Cervical Cancer Awareness and Screening in Jamaica: Effectiveness of a TheoryBased Educational Intervention. Int J Environ Res Public Health. 2015;13: ijerph13010053.

11. Shakya S, Karmacharya BM, Afset JE, Bofin A, Asvold BO, Syversen U, Tingulstad S. Community-Based Health Education has Positive Influence on the Attitude to Cervical Cancer Screening among Women in Rural Nepal. J Cancer Educ. 2016:31:547-53.

12. Rosser Jl, Njoroge B, Huchko MJ. Knowledge about cervical cancer screening and perception of risk among women attending outpatient clinics in rural Kenya. Int J Gynaecol Obstet. 2015;128:211-5.
13. Wongwatcharanukul L, Promthet S, Bradshaw P, Jirapornkul C, Tungsrithong $N$. Factors affecting cervical cancer screening uptake by Hmong hilltribe women in Thailand. Asian Pac J Cancer Prev. 2014;15:3753-6.

14. Bosch FX, Muñoz N, Sd S, Izarzugaza I, Gili M, Viladiu P, Tormo MJ, Moreo P, Ascunce N, Gonzalez LC, et al. Risk factors for cervical cancer in Colombia and Spain. International Journal of Cancer. 2006;52:18. JUL 2006

15. Mohanty G, Ghosh SN. Risk factors for cancer of cervix, status of screening and methods for its detection. Arch Gynecol Obstet. 2014;291:247-9.

16. Maree JE, Kaila I. Zambian women's experiences and understanding of cervical cancer: a qualitative study. Int J Gynecol Cancer. 2014;24:1065-71.

17. Driscoll SDMMA-CW-C:Barriers and facilitators to cervical cancer screening in high incidence populations: A synthesis of qualitative evidence. Women Health 2015:1-20.

18. Can H, Erdem O, Oztekin C, Celik SB, Onde M, Celepkolu T, Ongel K. Are primary health care workers aware of cervical cancer risk? Asian Pac J Cancer Prev. 2014;15:6669-71.

19. Fylan F. Screening for cervical cancer: a review of women's attitudes, knowledge, and behaviour. Br J Gen Pract. 1998;48:1509-14.

20. Williams M, Kuffour G, Ekuadzi E, Yeboah M, ElDuah M, Tuffour P. Assessment of psychological barriers to cenvical cancer screening among women in Kumasi, Ghana using a mixed methods approach. Afr Health Sci. 2013;13:1054-61.

21. Kantelhardt EJ, Moelle U, Begoinn M, Addissie A, Trocchi P, Yonas B, Hezkiel P, Stang A, Thomssen C, Vordermark D, et al. Cervical cancer in Ethiopia: survival of 1,059 patients who received oncologic therapy. Oncologist. 2014; 19:727-34.

22. Mutyaba T, Mmiro FA, Weiderpass E. Knowledge, attitudes and practices on cervical cancer screening among the medical workers of Mulago Hospital, Uganda. BMC Med Educ. 2006;6:13.

23. Marlow LA, Waller J, Wardle J. Public awareness that HPV is a risk factor for cervical cancer. Br J Cancer. 2007:97:691-4.

24. Gawdzik D, Chmaj-Wierzchowska K, Jurczyk MU, Sporny S, Opala T. Knowledge assessment of women living in the Wielkopolska region concerning risk factors for cervical cancer. Prz Menopauzalny. 2015;14:7-12.

25. Kress CM, Sharling L, Owen-Smith AA, Desalegn D, Blumberg HM, Goedken J. Knowledge, attitudes, and practices regarding cervical cancer and screening among Ethiopian health care workers. Int J Womens Health. 2015; 7:765-72.

26. Bostick RM, Sprafka JM, Virnig BA, Potter JD. Knowledge, attitudes, and personal practices regarding prevention and early detection of cancer. Prev Med. 1993;22:65-85.

27. Raychaudhuri S, Mandal S. Socio-demographic and behavioural risk factors for cervical cancer and knowledge, attitude and practice in rural and urban areas of North Bengal, India. Asian Pac J Cancer Prev. 2012;13:1093-6.

28. Al-Darwish AA, Al-Naim AF, Al-Mulhim KS, Al-Otaibi NK, Morsi MS, Aleem AM. Knowledge about cervical cancer early warning signs and symptoms, risk factors and vaccination among students at a medical school in Al-Ahsa, Kingdom of Saudi Arabia. Asian Pac J Cancer Prev. 2014;15:2529-32.

29. Daley E, Perrin K, Vamos C, Hernandez N, Anstey E, Baker E, Kolar S, Ebbert J. Confusion about Pap smears: lack of knowledge among high-risk women. J Women's Health (Larchmt). 2013;22:67-74.

30. Nilaweera RI, Perera S, Paranagama N, Anushyanthan AS. Knowledge and practices on breast and cervical cancer screening methods among female health care workers: a Sri Lankan experience. Asian Pac J Cancer Prev. 2012; 13:1193-6.

31. Eze JN, Umeora OU, Obuna JA, Egwuatu VE, Ejikeme BN. Cervical cancer awareness and cervical screening uptake at the Mater Misericordiae Hospital, Afikpo, Southeast Nigeria. Ann Afr Med. 2012;11:238-43.

32. Abotchie PN, Shokar NK. Cervical cancer screening among college students in ghana: knowledge and health beliefs. Int J Gynecol Cancer. 2009;19:412-6.

33. Lim JN, Ojo AA. Barriers to utilisation of cervical cancer screening in Sub Sahara Africa: a systematic review. Eur J Cancer Care (Engl). 2016;

34. Voidazan S, Morariu SH, Tarcea M, Moldovan H, Curticapian I, Dobreanu M. Human Papillomavirus (HPV) Infection and HPV Vaccination: Assessing the Level of Knowledge among Students of the University of Medicine and Pharmacy of Tirgu Mures, Romania. Acta Dermatovenerol Croat. 2016;24:193-202.

35. Rosser JI, Zakaras JM, Hamisi S, Huchko MJ. Men's knowledge and attitudes about cervical cancer screening in Kenya. BMC Womens Health. 2014;14:138

36. Yoruk S, Acikgoz A, Ergor G. Determination of knowledge levels, attitude and behaviors of female university students concerning cervical cancer, human papiloma virus and its vaccine. BMC Womens Health. 2016;16:51. 
37. Colon-Lopez V, Ortiz AP, Perez N, Acevedo E, Tamayo V, Zorrilla CD. Measuring Knowledge of Cancer Screening and Prevention Strategies in HIV Healthcare Professionals. P R Health Sci J. 2016;35:147-53.

38. Holroyd E, Twinn S, Adab P. Socio-cultural influences on Chinese women's attendance for cervical screening. J Adv Nurs. 2004;46:42-52.

39. Simayi $D$, Yang L, Li F, Wang YH, Amanguli A, Zhang W, Mohemaiti M, Tao $L$, Zhao J, Jing $M X$, et al. Implementing a cervical cancer awareness program in low- income settings in Western China: a community-based locally affordable intervention for risk reduction. Asian Pac J Cancer Prev. 2013;14:7459-66.

Submit your next manuscript to BioMed Central and we will help you at every step:

- We accept pre-submission inquiries

- Our selector tool helps you to find the most relevant journal

- We provide round the clock customer support

- Convenient online submission

- Thorough peer review

- Inclusion in PubMed and all major indexing services

- Maximum visibility for your research

Submit your manuscript at www.biomedcentral.com/submit
Biomed Central 